\section{Spiritual therapy}

Spiritual therapy attempts to bring peace and harmony between the living and the spiritual world, especially spirits of the ancestors, which are believed to live on after death and continue to influence events in the living world.

Without going into the merits and demerits of their beliefs about the ancestors, what really matters are the effects of the perceived harmony, which, translated into today's thinking, amounts to stress reduction. The effect of reduced stress, especially in relation to immunological response, is not in any doubt, even by today's science. Although psychiatrists may not accept an explanation that does not make sense in terms of modern science, the explanation is not the issue here: what matters are the perceived effects by those who practise spiritual therapy. George Brown and Tirril Harris from London used the word meaning to explain this phenomenon when they wrote about contextual threat (Brown \& Harris, 1978).

\section{Surgical}

A classic example of a traditional surgical intervention is craniotomy as practised by the Kisii and Turkana peoples of Kenya, for the treatment of psychosis related to diseases thought to be located inside the skull. This is, however, not practised today. What are still very much practised are small cuts on various parts of the body to relieve pain or for the insertion of medicines.

\section{Conclusions}

Traditional healers see and manage most of the mental health problems in East Africa. Our understanding of the pharmacology of the herbs they use is limited, but this is not so with psychotherapy. Indeed, the West has a lot to learn from traditional healers in East Africa.

The challenge is to psychiatrists trained on the Western model. Are they willing to learn from the traditional healers? Are they willing to work with them? They can say no to this only to the detriment of the patients they seek to heal, and more significantly to the detriment of science, which they seek to embrace. An even greater challenge is whether they can work together so that they each benefit from what is good from the other.

\section{References}

Brown, G. W. \& Harris, T. O. (1978) The Social Origins of Depression. A Study of Psychiatric Disorders in Women. Tavistock.

Ndetei, D. M. \& Muhanji, J. (1979) The prevalence and clinical presentation of psychiatric illness in a rural setting in Kenya. British Journal of Psychiatry, 135, 269-272.

Otsyula, W. (1973) Native and Western healing: the dilemma of East African psychiatry. Journal of Nervous and Mental Disease, 156 , 297-299.

Prince, R. (1960) The use of Rauwolfia for the treatment of psychoses by Nigerian traditional doctors. American Journal of Psychiatry, 117, 147-149.

Rappoport, H. \& Dent, P. L. (1979) An analysis of contemporary East Africa folk psychotherapy. British Journal of Medical Psychology, 52, 49-54.

\title{
Psychiatry in Austria
}

\section{W. Wolfgang Fleischhacker ${ }^{1}$ and Johannes Wancata ${ }^{2}$}

${ }^{1}$ Department of Biological Psychiatry, Medical University Innsbruck, Austria, email wolfgang.fleischhacker@uibk.ac.at ${ }^{2}$ Department of Social Psychiatry, Medical University Vienna, Austria

\begin{abstract}
ustria covers an area of some $84000 \mathrm{~km}^{2}$ and has a population of 8.1 million. According to World Bank criteria, Austria is a high-income country. The overall health budget represents $8 \%$ of gross domestic product (World Health Organization, 2005). The state of Austria is divided into nine federal provinces, which have significant legislative rights, including in healthcare provision.

Life expectancy at birth is 76.2 years for males and 82.3 years for females (in 2005). The proportion of the population under the age of 15 years is $15 \%$ and the proportion above 65 years is $17 \%$. Austria is among the 19 countries worldwide which are projected to have at least $10 \%$ of their population aged 80 years or over by the year 2050. Since some mental disorders, such as dementia, increase with age, the number of psychiatric patients will probably rise dramatically.
\end{abstract}

\section{Mental health policy and services}

The number of psychiatric hospital beds has decreased substantially. In the year 2001 there were 4696 psychiatric beds in total (i.e. 59 per 100000 population), down from nearly 12000 beds in 1974 - a decrease of more than $60 \%$.

The National Hospital Plan includes suggestions for the establishment of psychiatric units in general hospitals. Ten psychiatric units in general hospitals have been established, and several others are planned. Most traditional mental hospitals have been transformed to meet the needs of patients with acut mental illness. In addition, some of them have extended their services to people with physical diseases.

Each of the nine provinces has developed a mental health plan. Although there are regional differences between these, the key points of all plans are: a focus on community 
psychiatry, the decentralisation of psychiatric services and the social reintegration of persons suffering from mental disorders. The planning and provision of community psychiatric services are the responsibility of the provinces. Although some provinces now have a comprehensive network of community services, others are less advanced. The majority of these services (for vocational rehabilitation, supported housing, counselling, etc.) are provided by private organisations, but are predominantly funded by government agencies. The staff includes a variety of different professions (e.g. psychiatrists, social workers, nurses, psychotherapists, psychologists).

Primary healthcare is usually offered by self-employed general practitioners (GPs), working in solo practices. Most GPs treat patients with psychiatric disorders, but they may decide to refer patients to self-employed psychiatrists or other psychiatric services. Spread between office-based psychiatry, community-based services and psychiatric departments in hospitals, Austria has 11.8 psychiatrists per 100000 inhabitants. In addition, some GPs have trained in psychosocial medicine/psychotherapy.

In 1991, the Psychotherapy Act established a certified profession of psychotherapists. In Austria, psychotherapy is provided by a variety of different professions. Anyone is allowed to provide it after completing training in psychotherapy and being certified by the Ministry of Health. Nearly all psychiatrists and many psychologists have a certificate in psychotherapy. In the year 2002, overall 5495 persons (i.e. 68 per 100000 population) were certified psychotherapists.

The healthcare system (including mental healthcare) is predominantly financed via health insurance. This is mandatory for all employed and self-employed persons. There are no specific allocations for mental health within the health budget. The majority of the costs for primary care and secondary care (including psychiatric services) are covered by health insurance. This includes the costs of all psychotropic drugs. Interventions by psychologists as well as by psychotherapists are partly reimbursed. Psychiatric in-patient treatment is fully covered. Disability benefits are available for persons with mental disorders, but local regulations differ.

The fact that psychiatric community services are usually not directly financed by health insurance but via government agencies often complicates overall service provision.

\section{Mental health legislation}

There is no comprehensive mental health act in Austria. Compulsory admissions to psychiatric hospital departments are regulated by the Compulsory Admission Act 1991. According to this law, only persons who pose a threat to their own or other people's health or life because of a mental illness can be admitted compulsorily. Professionals called 'patient advocates' were established by this legislation and they act on behalf of patients in order to protect their rights. The number of compulsorily admitted patients has significantly increased since the new law became effective.

Persons with mental disorders who have committed a crime and are sentenced to jail fall under two main categories: those who are regarded as fit to stand trial; and those who are not. Both groups are detained in special institutions in the prison system, although those who are not regarded as fit to stand trial may also be detained in psychiatric hospitals.

\section{Research}

Psychiatric research is mainly based in universities - three public and one private. The public universities (in Innsbruck, Graz and Vienna) presently receive lump funds from the Austrian government, but there are plans to award at least a proportion of the money based on research output and teaching achievements. All three institutions supplement these funds through third-party funding. The private medical university in Salzburg basically taps into the same funding sources but has no direct support from the Austrian government, although it does receive some from the local government of Salzburg.

The majority of research at these four universities is clinical: Innsbruck focuses strongly on schizophrenia, dementia, neuropsychoimmunology, alcoholism, psycho-oncology and quality of life, whereas Vienna has a strong interest in affective disorders, social psychiatry, genetics and illegal substance misuse. Both centres have neuropsychology/neuroimaging groups. Consultation-liaison psychiatry, forensic psychiatry as well as research in adjustment and somatoform disorders are the stronghold of the Medical University in Graz. Researchers in Salzburg deal mainly with suicidality and bipolar illness. Most academic institutions have close ties to basic science departments with a strong focus on preclinical neurobiology and neuropsychopharmacology.

Some research is also done in non-academic institutions. It includes studies of drug safety and stigma.

\section{Education and training}

Psychiatry is an integral part of the medical curriculum in Austria's universities. Students are first exposed to the field as part of courses on the nervous system in the first year. They also receive some basic training with regard to communication strategies, for which psychiatrists are among the teachers. In the clinical semesters, psychiatry is taught in both theoretical and practical courses, and in the last year students can do a 4-week elective in psychiatry.

Postgraduate training is governed by law in Austria. The Austrian Medical Association (Österreichische Ärztekammer) prepares - after consulting with professional societies such as the ÖGPP - a curriculum, which has to be approved by the Ministry of Health. The latter has passed new regulations, effective as of 27 February 2007. Postgraduate specialist training in psychiatry now comprises 5 years of psychiatry, complemented by a half year each in neurology and internal medicine. Trainees have to take a final examination before being licensed as psychiatrists. The main change to the old curriculum is that the new one includes formalised psychotherapy training as an integral component. This has also led to a change in title from 'Specialist in Psychiatry' to 'Specialist in Psychiatry and Medical Psychotherapy', which is relevant to the question of reimbursement, insofar as specialists who hold a psychotherapy title are also eligible for health insurance coverage for psychotherapeutic services.

Most of the training is provided by hospitals, both academic and non-academic. As most psychiatric departments include both in- and out-patient facilities, trainees are expected to gain experience in different aspects of the field. A training in consultation-liaison psychiatry is also encouraged but, unfortunately, is not available everywhere. In addition, more 
specialised services, such as alcohol detoxification/rehabilitation, old age psychiatry and the like, are part of the training programme wherever such facilities exist.

Child and adolescent psychiatry has now also been given full specialist status, whereas it used to be a mere add-on specialty to psychiatry, neurology or paediatrics. Training includes 4 years in child and adolescent psychiatry as well as 10 months in paediatrics, 6 in neurology and 8 in adult psychiatry.

\section{Psychiatric associations}

Two major psychiatric associations exist in Austria. The Österreichische Gesellschaft für Psychiatrie und Psychotherapie (ÖGPP, Austrian Association for Psychiatry and Psychotherapy, http://www.oegpp.at), an association of psychiatrists, has close to 900 members and is the professional forum for most Austrian psychiatrists. It officially represents psychiatry in the Austrian Medical Association and is consulted in most psychiatry-related matters by both government and nongovernmental organisations.
Pro Mente Austria (http://www.promenteaustria.at) is the umbrella organisation of most community psychiatric services in Austria. The focus of Pro Mente Austria is mental health policy, partly in cooperation with ÖGPP. It has many nonpsychiatrist members.

Hilfe für Psychisch Erkrankte (HPE, an association for family carers, http://www.hpe.at) is Austria's largest and best organised transnational advocacy group.

\section{Sources}

Federal Ministry of Health and Women (2001, 2003) Mental Health in Austria. Selected Annotated Statistics from the Austrian Mental Health Reports 2001 and 2003.

Österreichisches Bundesinstitut für Gesundheitswesen (1998) Strukture/ler Bedarf in der psychiatrischen Versorgung. (Structural Needs for Organizing Psychiatric Services.)

Österreichisches Bundesinstitut für Gesundheitswesen (2001) Evaluierung der dezentralen Fachabteilungen für Psychiatrie. (Evaluation of Psychiatric Units in General Hospitals.)

World Health Organization (2005) Austria. In Mental Health Atlas 2005. See http://globalatlas.who.int/globalatlas/predefinedReports/ MentalHealth/Files/AT Mental Health Profile.pdf

\section{Mental healthcare in Singapore}

\section{Siow-Ann Chong}

Senior Consultant Psychiatrist, Vice Chairman, Medical Board (Research) of the Institute of Mental Health, Buangkok Green Medical Park, 10 Buangkok View, Singapore 539747, email siow_ann_chong@imh.com.sg

ingapore is a modern city state and the smallest nation (land area of $699 \mathrm{~km}^{2}$ ) in South East Asia. Its population of over 4 million is multiracial, with the Chinese (76.8\%) constituting the majority of the population, followed by the Malays (13.9\%) and the Indians (7.9\%). The present health system is one that stresses individual responsibility, based on a system of compulsory medical saving accounts and on market mechanisms for the allocation of scarce healthcare resources. There are both public and private healthcare sectors. Since 1985, every public sector hospital has been 'restructured' - to grant some degree of autonomy in operational matters, with the intention of creating competition and financial discipline, although the government still retains $100 \%$ ownership of the hospitals.

\section{Mental health services}

Singapore has not engaged in a large move towards deinstitutionalisation, and community care for patients with a mental illness has not received high priority. The Institute of Mental Health (IMH) is the largest mental hospital, with a total bed capacity of 2200, and is the largest provider of mental healthcare. It provides a range of sub-specialties, such as child and adolescent psychiatry, geriatric psychiatry, substance misuse, affective disorders, sleep disorders, early psychosis, psychiatric rehabilitation and forensic psychiatry. It provides a range of pharmacological and psychological treatments, as well as psychosocial rehabilitation.
More recently, however, there has been a resurgence in the recognition of the need for community psychiatry, with the establishment of a department of community psychiatry in 2001 within the IMH. The department provides an array of services, including community-based programmes such as the assertive community treatment (ACT) programme, the mobile crisis team (MCT) programme (a rapid-response team for crises in the home) and the community psychiatric nurse (CPN) service (Lim et al, 2005).

The IMH is the only statutory institution, in that patients can be admitted, detained and discharged in accordance with the Mental Disorders and Treatment Act 1985 and the Criminal Procedure Code 1985 of Singapore. The services include assessment of accused persons suspected to be of unsound mind and the psychiatric treatment of offenders who are mentally unwell. Powers to detain persons for treatment exist under the Mental Disorders and Treatment Act. There is currently no community treatment order or other provision to mandate the compulsory treatment of patients in the community.

Three of the restructured general hospitals in the public sector provide a psychiatric service. The numbers of mental health workers and beds in these services are small, however; for example, the number of beds in each ranges from 15 to 26. There are also psychiatric services in the Singapore armed forces, prison services and hospitals in the private sector (there is only one private hospital which solely provides care for people who are mentally ill).

Another important facet of mental healthcare in Singapore is the complementary and supplementary services provided 